Atmos. Chem. Phys., 10, 707-718, 2010

www.atmos-chem-phys.net/10/707/2010/

(C) Author(s) 2010. This work is distributed under

the Creative Commons Attribution 3.0 License.

\title{
Planetary wave activity in the polar lower stratosphere
}

\author{
S. P. Alexander ${ }^{1}$ and M. G. Shepherd ${ }^{2}$ \\ ${ }^{1}$ Australian Antarctic Division, Kingston, Tasmania, Australia \\ ${ }^{2}$ Centre for Research in Earth and Space Science, York University, Toronto, Canada
}

Received: 28 May 2009 - Published in Atmos. Chem. Phys. Discuss.: 7 July 2009

Revised: 23 December 2009 - Accepted: 7 January 2010 - Published: 25 January 2010

\begin{abstract}
Temperature data from the COSMIC GPS-RO satellite constellation are used to study the distribution and variability of planetary wave activity in the low to midstratosphere $(15-40 \mathrm{~km})$ of the Arctic and Antarctic from September 2006 until March 2009. Stationary waves are separated from travelling waves and their amplitudes, periods and small-scale vertical distribution then examined. COSMIC observed short lived (less than two weeks and less than $5 \mathrm{~km}$ vertically) but large enhancements in planetary wave amplitudes occurring regularly throughout all winters in both hemispheres. In contrast to recent Arctic winters, eastward wave activity during 2008-2009 was significantly reduced during the early part of the winter and immediately prior to the major SSW. The eastward waves which did exist had similar periods to the two preceding winters ( 16-20 days). A westward wave with zonal wavenumber two, with distinct peaks at $22 \mathrm{~km}$ and $35 \mathrm{~km}$ and period around 16-24 days, as well as a stationary wave two were associated with the 2009 major SSW. In the Southern Hemisphere, the height structure of planetary wave amplitudes also exhibited fluctuations on short time and vertical scales superimposed upon the broader seasonal cycle. Significant inter-annual variability in planetary wave amplitude and period are noticed, with the times of cessation of significant activity also varying.
\end{abstract}

\section{Introduction}

Large amplitude planetary waves dominate the winter middle atmosphere and their interaction with the zonal mean flow is a major driver of winter stratospheric dynamics. Planetary wave amplitudes are larger in the Northern Hemisphere than in the Southern Hemisphere due to larger thermal and

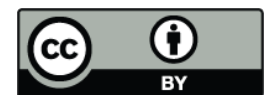

Correspondence to: S. P. Alexander (simon.alexander@aad.gov.au) orographic forcing (Andrews et al., 1987). Stratospheric waves generally propagate eastward relative to the ground in the Southern Hemisphere (Hartmann, 1976; Shiotani et al., 1990), while quasi-stationary waves dominate the Northern Hemisphere (Chshyolkova et al., 2005).

Planetary waves propagate upward from tropospheric sources (Hartmann et al., 1984; Randel, 1987; Krüger et al., 2005). Several studies showed the connection between tropospheric and stratospheric planetary wave activity. Leovy and Webster (1976) and Mechoso and Hartmann (1982) discussed the strong vertical coherence of travelling planetary waves. Randel (1987) used geopotential height below $1 \mathrm{hPa}$ to find a decrease in propagation time from the troposphere to stratosphere for higher zonal wavenumber waves. Westward propagating waves with zonal wavenumber $s=1$ and $s=2$ were identified in the stratosphere using satellite data and shown to agree with Rossby modes for an isothermal atmosphere (Hirota and Hirooka, 1984). Recent satellite datasets have enabled wave characteristics and propagation to be followed up to the mesosphere and lower thermosphere (Hirooka, 2000).

Sudden stratospheric warmings (SSWs) are much more prevalent in the Arctic than in the Antarctic due to the larger Northern Hemisphere planetary wave forcing (Manney et al., 2005; Pancheva et al., 2008a). An increase in planetary wave activity is noticed prior to the onset of an SSW which preconditions the atmosphere (e.g. Chshyolkova et al., 2006; Hoffmann et al., 2007), leading to an upward and poleward motion of heat flux (Andrews et al., 1987). A downward circulation causing adiabatic heating in the stratosphere results from the deceleration of the eastward flow by planetary waves (Liu and Roble, 2002). A reversal of the meridional temperature gradient at $10 \mathrm{hPa}$ occurs for minor warmings and additionally for major warmings, there is a reversal of the eastward flow (Labitzke and Naujokat, 2000).

The recent advent of GPS Radio Occultation satellite missions has resulted in the collection of highly accurate

Published by Copernicus Publications on behalf of the European Geosciences Union. 
(sub-Kelvin accuracy) and increasingly dense temperature profiles from near the surface to $40 \mathrm{~km}$ altitude (Kursinski et al., 1997; Tsuda et al., 2000). The launch of the Constellation Observing System for Meteorology, Ionosphere and Climate Global Positioning System Radio Occultation (COSMIC GPS-RO) satellites in April 2006 has resulted in about 2000 profiles per day (Anthes et al., 2008) fully distributed about the globe in longitude and local time, making them ideal for global scale wave studies (Alexander et al., 2008b). COSMIC data were used to show large planetary wave activity in the 2006 Antarctic early summer, more consistent with winter-time activity (Shepherd and Tsuda, 2008). COSMIC data are also dense enough to quantify changes in gravity wave activity over short time scales (on the order of several days) and were used to study gravity wave activity associated with recent Arctic SSWs (Alexander et al., 2009; Wang and Alexander, 2009).

\section{Data analysis}

The COSMIC version 2.0 dry temperature data product is used, which is derived from the measured refractivity profile by neglecting humidity. Sufficient data for this analysis are available from mid-August 2006 onwards. The original GPS-RO data are available at $0.1 \mathrm{~km}$ vertical resolution but they have an effective vertical resolution on the order of $1 \mathrm{~km}$ in the lower stratosphere (Kursinski et al., 1997). Therefore the data are interpolated to the approximate real resolution of $1 \mathrm{~km}$. The precision of the COSMIC refractivity is $0.7 \%$ at $30 \mathrm{~km}$ (Schreiner et al., 2007). The accuracy of the derived temperature is better than $0.5 \mathrm{~K}$ (Kursinski et al., 1997). Only a small bias of $1-2 \%$ between radiosondes and COSMIC at $25 \mathrm{~km}$ altitude was observed by Hayashi et al. (2009), thus gravity wave and planetary wave activity observed with COSMIC agrees well with model results (Alexander et al., 2008b,a; Kawatani et al., 2009). COSMIC data are available from near the surface to $40 \mathrm{~km}$, although we consider altitudes above $15 \mathrm{~km}$ here to avoid humidity effects in the lower regions.

The space-time spectral analysis method is a technique for studying planetary scale waves in the atmosphere (Hayashi, 1971). This method allows the simultaneous separation of the background field into eastward and westward propagating waves and has been used to study planetary waves from the mid-latitude surface to middle stratosphere (e.g. Mechoso and Hartmann, 1982; Speth and Madden, 1983; Hirota and Hirooka, 1984; Hirooka and Hirota, 1985; Watanabe et al., 2008).

For a fixed latitude, the temperature $T$, which is a function of longitude $\lambda$ and time $t$, can be expressed as a double Fourier expansion:

$T(\lambda, t)=\sum_{s} \sum_{ \pm \omega} R_{s, \pm \omega} \cos \left(s \lambda \pm \omega t+\phi_{s, \pm \omega}\right)$ where $R_{s, \pm \omega}$ is the amplitude, $s$ is the zonal wavenumber, $\omega$ is the frequency and $\phi$ is the phase. The positive and negative signs correspond to eastward and westward propagating waves respectively. The space-time power spectrum is given by (Hayashi, 1971):

$P_{s, \pm \omega}(T)=\sum_{\Delta \omega} \frac{1}{2} R_{s, \pm \omega}^{2}$

where $\Delta \omega$ indicates the summation over a particular frequency band. Practically, the $R_{s, \pm \omega}$ and $\phi_{s, \pm \omega}$ are obtained by taking the FFT in longitude:

$T(\lambda, t)=\sum_{s} C_{S}(t) \cos (s \lambda)+S_{S}(t) \sin (s \lambda)$

and using these Fourier coefficients as input for further FFTs in time:

$C_{s}(t)=\sum_{\omega} A_{s, \omega} \cos (\omega t)+B_{s, \omega} \sin (\omega t)$

$S_{S}(t)=\sum_{\omega} a_{s, \omega} \cos (\omega t)+b_{s, \omega} \sin (\omega t)$

where the co-efficients $A_{s, \omega}, B_{s, \omega}, a_{s, \omega}$ and $b_{s, \omega}$ can be related to $R_{s, \pm \omega}$ and $\phi_{s, \pm \omega}$ (the reader is referred to Hayashi (1971) for full details).

The eastward and westward discrete wave components for $s=1$ and $s=2$ are thus able to be extracted. We use the wavelet transform to determine the eastward and westward wave amplitudes from the combined output of the spacetime analysis. A Morlet wavelet is used as the orthonormal wavelet because the temperature perturbation data are amplitude-modulated sine waves. Specifically, the Morlet wavelet $\psi_{0}(t)$ is a plane-modulated Gaussian function:

$\psi_{o}(t)=\pi^{1 / 4} e^{6 i t} e^{-t^{2} / 2}$

Amplitude and phase information can be extracted from the one dimensional time series because the Morlet wavelet is complex (Torrence and Compo, 1998). Data are zero padded to remove end wraparound effects prior to calculating the wavelet transform. Quasi-stationary planetary waves are obtained because a westward and eastward propagating wave with the same amplitude represents these stationary oscillations. Thus, the amplitudes are re-calculated from the results of the initial wavelet analysis using the following rules, where $A_{\mathrm{w}}$ are westward amplitudes, $A_{\mathrm{e}}$ are eastward amplitudes and $A_{\mathrm{s}}$ are stationary amplitudes for a specified s. If from the wavelet analysis, $A_{\mathrm{w}}>A_{\mathrm{e}}$, then the new amplitudes are given by $A_{\mathrm{w}(\text { new })}=A_{\mathrm{w}}-A_{\mathrm{e}}, A_{\mathrm{s}}=2 A_{\mathrm{e}}$ and $A_{\mathrm{e}(\text { new })}=0$. On the other hand, if $A_{\mathrm{w}}<A_{\mathrm{e}}$, then $A_{\mathrm{e}(\text { new })}=A_{\mathrm{e}}-A_{\mathrm{w}}$, $A_{\mathrm{s}}=2 A_{\mathrm{w}}$ and $A_{\mathrm{w} \text { (new) }}=0$ (Pogoreltsev et al., 2009). If there is a modulation in the phase of a stationary wave, it is interpreted as a travelling wave in this analysis.

Zonal wavenumbers of $s \geq 4$ are indicative of tropospheric baroclinic waves (Randel, 1987; Watanabe et al., 2008), thus 
we consider only $s \leq 3$ here. Furthermore, the $s-\omega$ spectra to be discussed below have nearly all of the power associated with low $|s|$ waves. Hövmoller diagrams are reconstructed using these wave filtered regions (not shown) to check that the filtering gives meaningful results when compared to the original binned temperature data. While results obtained for the $|s|=3$ waves are physically reasonable, the total amplitudes are generally $<2 \mathrm{~K}$, making them insignificant compared to the $|s|=1$ and $|s|=2$ waves, so they are not considered further.

At each altitude, COSMIC $T$ data are binned into grid cells with latitude width $10^{\circ}$ and longitude width $20^{\circ}$ and temporal resolution of two days, which is then used in the space-time and wavelet analyses detailed above. (Note that this method inherently adds some noise to low $s$ waves.) The two-day zonal mean temperature is removed to form $T^{\prime}$. Unlike equatorial wave analysis, it is not necessary to separate the temperature data into symmetrical and anti-symmetrical components (Ern et al., 2009). The temperature spectra are not red so it is not necessary to divide the results by a background spectrum (Alexander et al., 2008b; Ern et al., 2008). Henceforth we use the notation E1 to represent any eastward $s=1$ planetary wave, W1 to represent any westward $s=1$ planetary wave, and so on.

\section{Background temperature structure}

\subsection{Hövmoller diagrams}

Hövmoller diagrams of the temperature perturbations from the zonal mean observed by COSMIC are shown in Fig. 1 for winter at $60^{\circ} \mathrm{N}-70^{\circ} \mathrm{N}$ (top row) and spring at $60^{\circ} \mathrm{S}-70^{\circ} \mathrm{S}$ (bottom row). Different seasons are shown in each hemisphere due to the different times when planetary wave activity is dominant in the lower stratosphere.

The Northern Hemisphere $T^{\prime}$ have amplitudes of up to $40 \mathrm{~K}$. In general, positive perturbations occurred around $180^{\circ} \mathrm{E}$, as a result of the zonally asymmetric structure associated with the stationary $s=1$ Aleutian High and corresponding low over Scandinavia (Pawson and Kubitz, 1996). The 2009 major sudden stratospheric warming can be seen in Fig. 1c with a complete reversal of the eastward flow and near-absence of planetary waves from late January onward. In the Southern Hemisphere, the $\left|T^{\prime}\right|$ rarely exceeded $20 \mathrm{~K}$. Eastward propagation of planetary waves in the Southern Hemisphere is apparent, with $s=1$ dominant at most times. Positive perturbations are generally observed in the Eastern Hemisphere, with corresponding negative perturbations in the Western Hemisphere.

The Hövmoller diagrams reconstructed from the wavelet analysis, incorporating only eastward and westward travelling waves with periods of 4-32 days, are shown in Fig. 2. The travelling waves visible in the temperature perturbations of both hemispheres in Fig. 1 are also seen here. The dom-
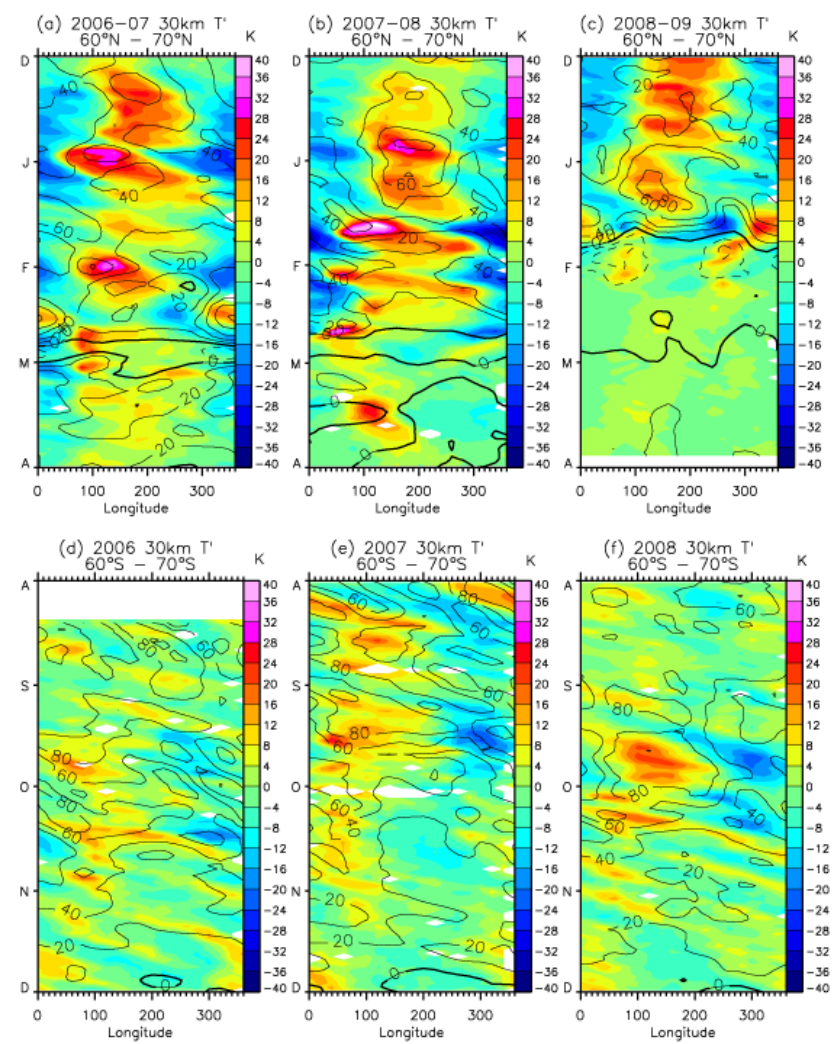

Fig. 1. Hövmoller diagrams of $T^{\prime}$ at $60^{\circ} \mathrm{N}-70^{\circ} \mathrm{N}$ (top row) and $60^{\circ} \mathrm{S}-70^{\circ} \mathrm{S}$ (bottom row) at $30 \mathrm{~km}$ for the three winter/spring years considered. White indicates missing data. The five day smoothed UKMO zonal winds at the nearest pressure level $(10 \mathrm{hPa})$ are marked in black (units $\mathrm{m} \mathrm{s}^{-1}$, solid eastward, dashed westward).

inant travelling waves in the Northern Hemisphere propagate eastward and reach amplitudes of about $20 \mathrm{~K}$. Westward propagating waves are visible during late February and March 2008 and during the same time in 2009, with amplitudes generally less than $10 \mathrm{~K}$. The travelling planetary waves in the Southern Hemisphere are almost entirely eastward propagating. They show significant variability in amplitude and timing of maximum wave activity between years and their amplitudes rarely exceed $10 \mathrm{~K}$.

\subsection{The Arctic Sudden Stratospheric Warmings}

Several sudden stratospheric warmings (SSWs) occurred during the three Arctic winters considered here. One major SSW occurred each winter, as well as several minor warmings during 2007 and 2008. The $10 \mathrm{hPa}$ UKMO zonal mean temperatures and zonal mean zonal winds (black contours) are displayed in Fig. 3 for these winters for illustration because the SSW definition involves $10 \mathrm{hPa}$ dynamical fields (Labitzke and Naujokat, 2000), although a check reveals COSMIC temperatures at $30-32 \mathrm{~km}$ to be essentially the same (not shown). The three major SSWs are clearly 

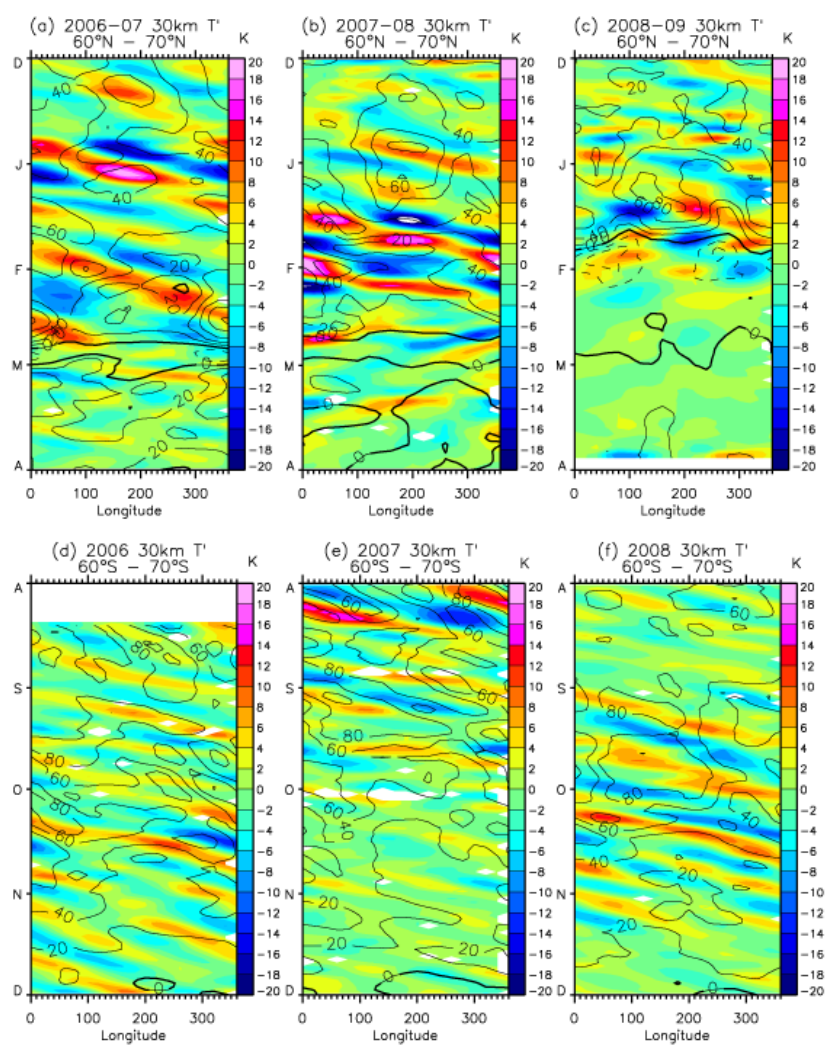

Fig. 2. As for Fig. 1 but only incorporating travelling wave components with periods of 4-32 days reconstructed from the wavelet analysis. Note that the colour scales are half those of Fig. 1.

observed by their westward winds in late February 2007, late February 2008 and late January-early February 2009. The dramatic nature of the 2009 warming is evident in Fig. 3c, after which the stratosphere did not recover to its winter-time state. Indeed, this warming was the strongest and most prolonged on record (Labitzke and Kunze, 2009; Manney et al., 2009).

Several minor SSWs are apparent in early January 2007, early February 2007, late January 2008, early February 2008 and mid February 2008, although the observed meridional temperature gradient reversals were relatively small during some of these minor SSWs.

\subsection{Morphology of the temperature anomalies}

The temperature anomalies at $60^{\circ} \mathrm{N}-70^{\circ} \mathrm{N}$ are shown in Fig. 4a. These anomalies are calculated as the 33month zonal mean profile (using data from July 2006 to March 2009) subtracted from the daily zonal mean profiles at the respective heights thus removing the mean annual cycle; this data length also included a full QBO cycle (Zhou et al., 2002; Alexander et al., 2008b). The anomalies were
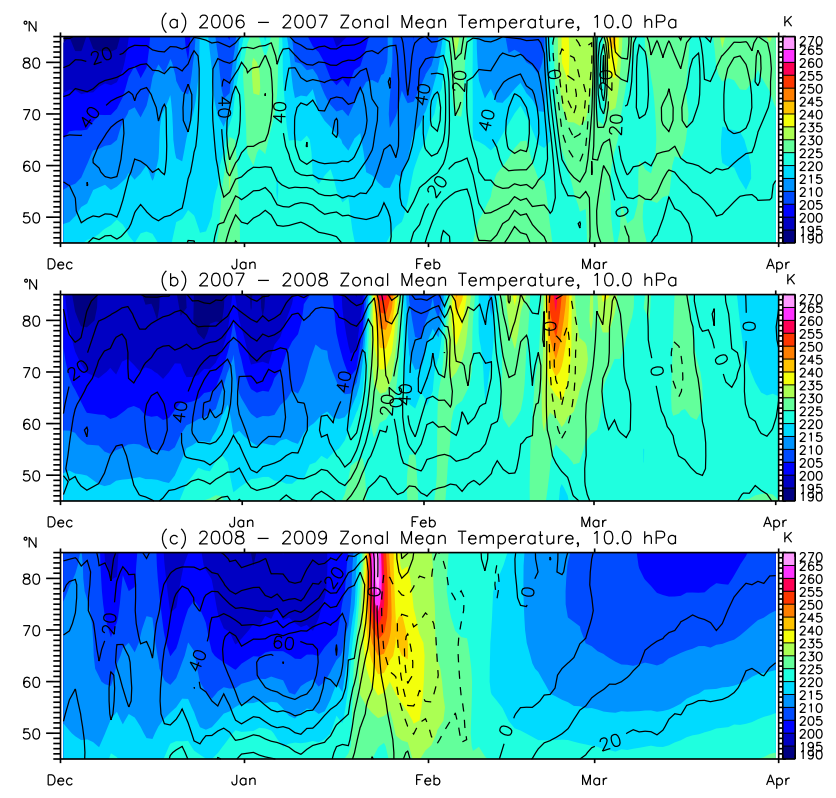

Fig. 3. The $10 \mathrm{hPa}$ UKMO zonal mean temperatures (colour contour) and zonal mean zonal winds (black lines, units $\mathrm{ms}^{-1}$, solid eastward, dashed westward) for the three Arctic winters.

then normalized to the standard deviation at different altitudes to exclude the effect of decreasing density, as displayed in Fig. 4b.

Warm temperature anomalies with a peak at $\sim 30 \mathrm{~km}$ appeared at the beginning of January and February and during the entire month of March 2007 as well as in late January and during February-March 2008 (Fig. 4a). The anomalies above $20 \mathrm{~km}$ height associated with the 2009 major SSW were the most dramatic. The warm temperature anomaly observed at the end of January 2009 with a peak around $30 \mathrm{~km}$ was the strongest among those observed during the three winter seasons and lasted almost until the end of February before a cold anomaly sets in until the end of March 2009. At lower altitudes the warm anomaly continued to be the strongest among the three seasons and extended beyond the end of March and possibly reached the upper troposphere.

The normalized temperature anomalies show a similar pattern but amplitudes are about a factor of 10 smaller than the residuals (Fig. 4b). The cold anomalies were confined to the November-January period extending throughout the altitude range considered here. However, in 2006 and above $\sim 20 \mathrm{~km}$ this period is reduced to November-December due to a warm anomaly associated with the stratospheric warming in January 2007. In 2007 the stratospheric warming signature with amplitude of 0.6 can be seen embedded in the cold anomaly in February 2007. During the major SSW in January-February 2008 the warm normalized anomaly reached 0.9-1.2. Strongest of all, the normalized anomalies during the late January-early February 2009 period reached 


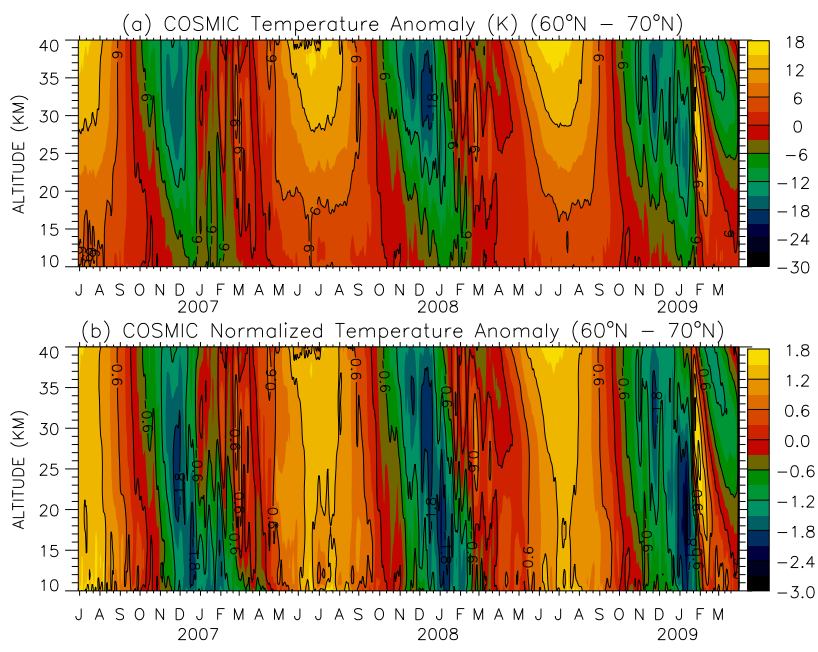

Fig. 4. (a) Temperature anomalies from the 33-month mean at $60^{\circ} \mathrm{N}-70^{\circ} \mathrm{N}$ and (b) normalized temperature anomalies.

1.8 between $20 \mathrm{~km}$ and $30 \mathrm{~km}$ altitude. The manifestations are more dramatic poleward, as expected (e.g. $65^{\circ} \mathrm{N}-75^{\circ} \mathrm{N}$, not shown here).

In the Southern Hemisphere the anomaly patterns are somewhat different (Fig. 5). There is annual variability marked by broader warm seasonal anomalies than the cold temperature anomalies. The 2007 winter anomaly appeared weaker and shorter in duration than in the winters of 2006 and 2008. This is apparent both in the mapping of the residual and normalized temperature anomalies. A distinct tilt with height is observed indicating downward progression of the zonal mean temperature anomalies, which is particularly apparent below $25 \mathrm{~km}$ altitude and suggests downward communication between the stratosphere and troposphere. Perturbations in the stratosphere lead to changes in the tropospheric circulation, affecting the strength and position of the stratospheric polar night jet resulting from the dynamical interaction of planetary waves and the zonal mean flow (e.g. Baldwin and Dunkerton, 1999).

\subsection{Space-time spectra}

The wavenumber-frequency $s-\omega$ spectra at two altitudes at $60^{\circ} \mathrm{N}-70^{\circ} \mathrm{N}$ and $60^{\circ} \mathrm{S}-70^{\circ} \mathrm{S}$ are shown in Fig. 6. These results contain stationary and travelling wave information, as discussed above. The general structure of the COSMIC temperature $s-\omega$ power spectra agree with previous observational and model analyses at similar altitudes where pressure, geopotential height or geostrophic wind were used (Hayashi and Golder, 1977; Fraedrich and Böttger, 1978; Mechoso and Hartmann, 1982; Watanabe et al., 2008).

All of the spectra were calculated over the interval 1 November 2006 to 4 November 2008 and were formed from the average of the eight 96 day intervals during this

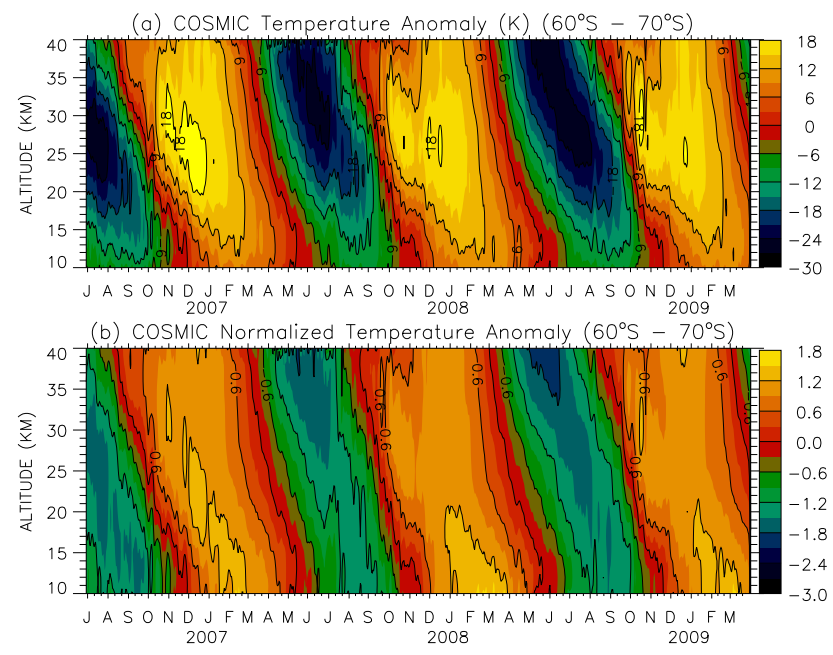

Fig. 5. Same as Fig. 4 but for $60^{\circ} \mathrm{S}-70^{\circ} \mathrm{S}$.
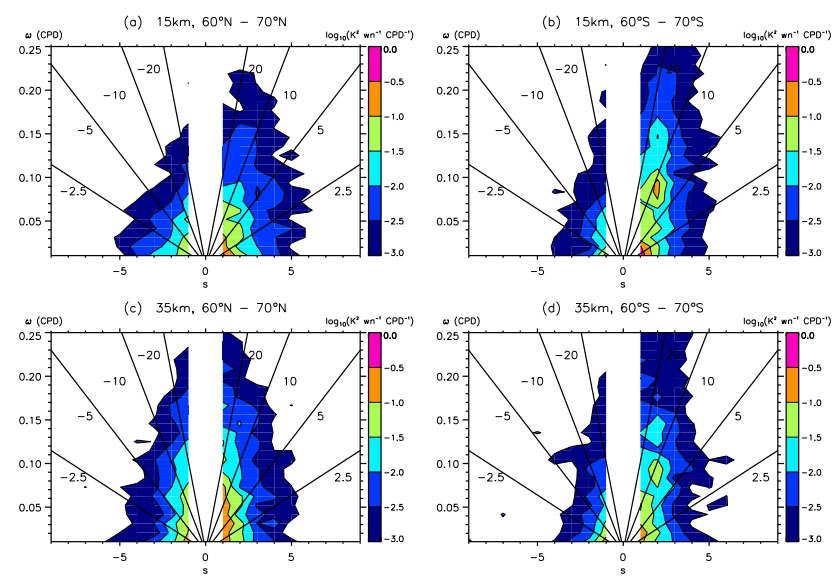

Fig. 6. $s-\omega$ spectra for the period 1 November 2006 to 4 November 2008 for $60^{\circ} \mathrm{N}-70^{\circ} \mathrm{N}$ at (a) $15 \mathrm{~km}$ and (c) $35 \mathrm{~km}$ and for $60^{\circ} \mathrm{S}-$ $70^{\circ} \mathrm{S}$ at (b) $15 \mathrm{~km}$ and (d) $35 \mathrm{~km}$ (right hand column). Negative $s$ indicates westward propagation. Black lines mark ground-based phase speeds (units $\mathrm{m} \mathrm{s}^{-1}$, positive eastward).

period, each starting on 1 November, 1 February, 1 May and 1 August for both years, in a similar manner to Speth and Madden (1983). The resultant slight overlapping of spectra is not significant. Averaging the spectra over the eight intervals reduces the noise and uncertainty of the results. This time interval covers two full years and so the results are not weighted toward any season in particular. Waves with ground based periods of 4 days (the Nyquist period) to 32 days and $|s|<9$ are considered here. When considering ground-based frequencies, as measured by COSMIC and other satellites, the location of a wave in wavenumber-frequency space will not change with altitude under the assumption of a slowly varying background field despite changes in the background wind with altitude (Ern et al., 2008). 


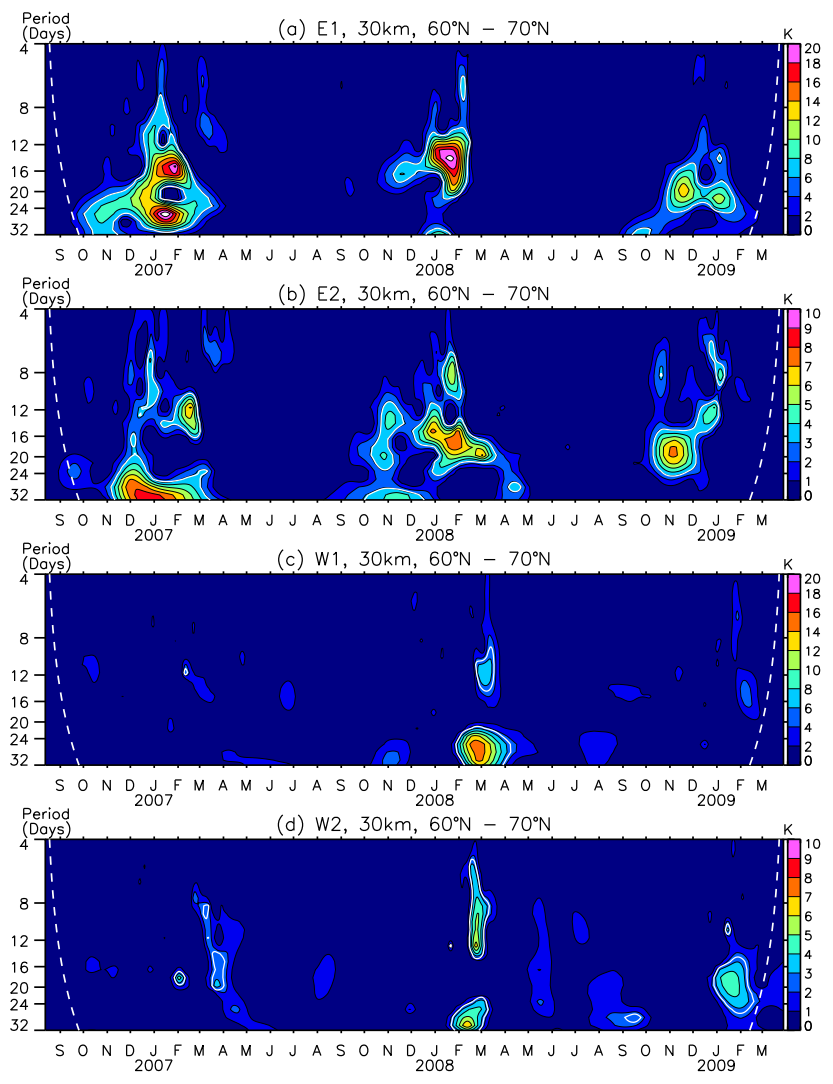

Fig. 7. The $60^{\circ} \mathrm{N}-70^{\circ} \mathrm{N}$ planetary wave temperature wavelet amplitudes for: (a) E1, (b) E2, (c) W1, (d) W2. The 95\% confidence lines are marked by the solid white lines, while the cones of influence are indicated by the white dashed lines (Torrence and Compo, 1998).

The largest variances and thus largest wave activity are due to waves with $|s| \leq 2$. The $35 \mathrm{~km} 60^{\circ} \mathrm{N}-70^{\circ} \mathrm{N}$ spectrum is more symmetrical and reveals more waves with higher ground based phase speeds $c_{x}$ than that at $15 \mathrm{~km}$. Even so, most planetary waves have $\left|c_{x}\right|<10 \mathrm{~m} \mathrm{~s}^{-1}$. In contrast, the $60^{\circ} \mathrm{S}-70^{\circ} \mathrm{S}$ power spectra are similar at $15 \mathrm{~km}$ and $35 \mathrm{~km}$. There is a clear preference for more eastward propagating waves than westward at both altitudes, as expected in the Southern Hemisphere (Hartmann et al., 1984; Shiotani et al., 1990).

\section{Northern Hemisphere planetary wave activity}

The amplitudes of the $60^{\circ} \mathrm{N}-70^{\circ} \mathrm{N}$ eastward and westward travelling planetary waves at $30 \mathrm{~km}$ are shown in Fig. 7, while the stationary wave amplitudes are displayed in Fig. 8. These results are calculated from the wavelet analysis and subsequent separation of stationary waves, following Pogoreltsev et al. (2009). Inter-annual variability in amplitude, period and timing of all of the waves is evident. Signif-

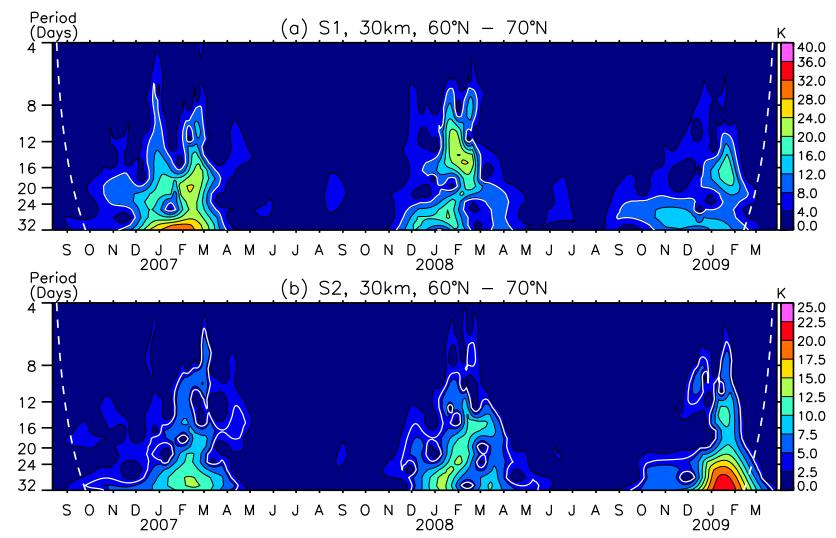

Fig. 8. The $60^{\circ} \mathrm{N}-70^{\circ} \mathrm{N}$ stationary planetary wave temperature wavelet amplitudes for: (a) S1 and (b) S2.

icant increases in E1 wave amplitude correspond to dominant periods ranging from $\sim 8$ days to $\sim 30$ days, with large peaks noted around 12 days, 16 days, 20 days and 30 days. An E2 wave was observed each winter with period 8-10 days, in addition to large wave activity with periods centred on 16 days and $>24$ days. During the winter of 2008-2009, the eastward waves were weaker than during the two previous winters and only existed before mid-January. The W1 and W2 were significant during February and early March 2008, co-incident in time with that winter's major SSW. The periods of these waves are 6-12 days (W2), 10-14 days (W1) and 24-30 days (both W1 and W2). A significant amount of W2 activity was also present during the 2009 major SSW (period $\sim 20$ days). The $\mathrm{S} 1$ waves had larger amplitudes during 2006-2007 and 2007-2008 than 2008-2009, however the major SSW period of 2009 contained the largest amount of S2 activity of any of these three winters.

The variability of planetary wave amplitudes with altitude is examined in detail using this high vertical resolution COSMIC data. The wavelet data were reconstructed for eastward and westward travelling planetary waves with periods of 432 days and are plotted as a function of height and time in Fig. 9 for $s=1$ and $s=2$, while the equivalent stationary wave amplitude results are shown in Fig. 10. The amplitudes were generally not a simple function of height, and varied between winters as well as on short timescales (on the order of days). Generally, a broad peak in amplitude of vertical extent $5-10 \mathrm{~km}$ and temporal extent of less than one month was noted for most planetary waves. There were also numerous smaller but still significant increases and decreases in planetary wave activity over scales as short as a few kilometers embedded within the monthly and seasonal scale structure.

During these three Arctic winters, the strongest E1 and E2 activity occurred in early January 2007, peaking at $27 \mathrm{~km}$ and $23 \mathrm{~km}$ respectively and co-inciding with the first minor SSW of that winter. Both E1 and E2 were suppressed 

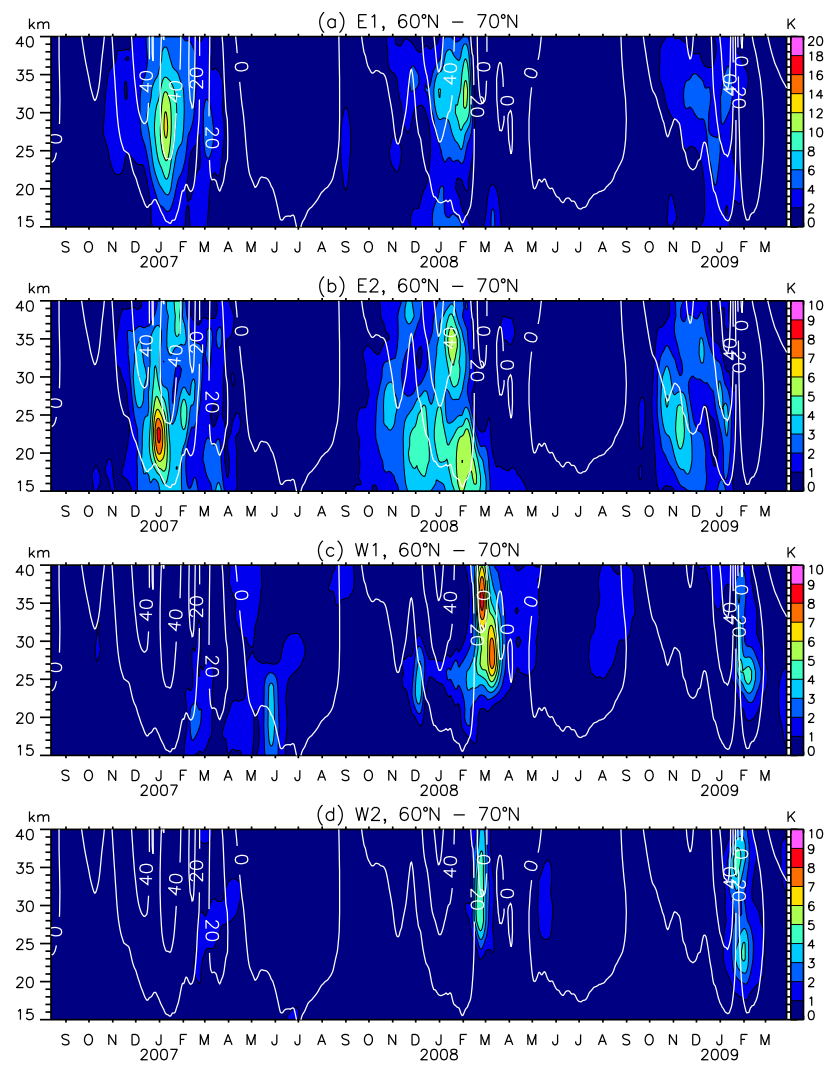

Fig. 9. The reconstructed 4-32 day travelling planetary wave amplitudes in height and time at $60^{\circ} \mathrm{N}-70^{\circ} \mathrm{N}$ for: (a) E1, (b) E2, (c) W1, (d) W2. Fifteen day smoothed UKMO zonal mean zonal winds (white, units of $\mathrm{m} \mathrm{s}^{-1}$, solid eastward) are also marked.

following the 2009 major SSW. Peak E1 amplitudes shifted to higher altitudes $(30-35 \mathrm{~km})$ for the winters of 2008 and 2009. A second, separate and weaker peak in E2 amplitude is noted above $28 \mathrm{~km}$ during January 2007 and January 2008, although not during 2009.

As observed in the $30 \mathrm{~km}$ wavelet amplitudes plots of Fig. 7 above, the largest westward wave activity co-incided with the February 2008 major SSW. In the height - time plots (Fig. 9), large amplitude W1 and W2 occurred from $25 \mathrm{~km}$ upward over a period of one to two weeks, reaching $9 \mathrm{~K}$ and $6 \mathrm{~K}$ respectively. The other period of large westward wave activity throughout the lower stratosphere was during the 2009 major SSW, where W2 exceeded $4 \mathrm{~K}$ down to $20 \mathrm{~km}$ (with two distinct peaks at $35 \mathrm{~km}$ and later in time at $22 \mathrm{~km}$ ). These waves are clearly observed in the temperature perturbations at $30 \mathrm{~km}$ in Fig. 1f. The increase in W1 activity observed during 2009 peaked in mid-February at $25 \mathrm{~km}$ and were of lower amplitude than those observed during 2008. There was a near absence of westward waves during the winter of 2006-2007 despite the minor and major SSWs during this winter.
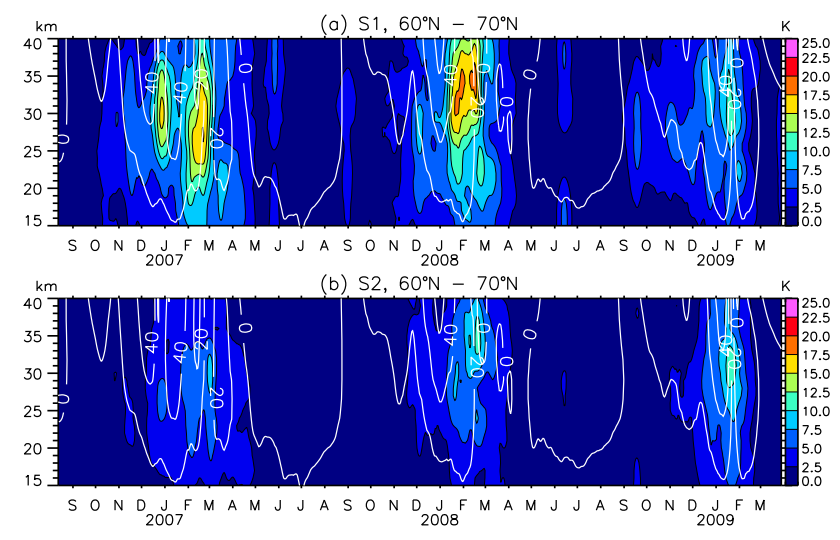

Fig. 10. The reconstructed 4-32 day mean stationary planetary wave amplitudes in height and time at $60^{\circ} \mathrm{N}-70^{\circ} \mathrm{N}$ for: (a) $\mathrm{S} 1$ and (b) S2. Fifteen day smoothed UKMO zonal mean zonal winds (white, units of $\mathrm{m} \mathrm{s}^{-1}$, solid eastward) are also marked.

Both the $S 1$ and $S 2$ had maximum amplitudes at $25-30 \mathrm{~km}$ in 2007 and 2009. This maximum amplitude shifted to 3035 km during late January and early February 2008 (S1) and early to mid-February 2008 (S2). The amplitudes of the stationary waves were enhanced during each winter in the week or two prior to each major SSW and decayed rapidly following onset. Prior to the 2009 warming, the S2 wave had larger amplitudes extending throughout the entire $15-40 \mathrm{~km}$ altitude range (with a maximum of around $12 \mathrm{~K}$ at $30 \mathrm{~km}$ ) than the two preceding winters. On the other hand, the S1 was significantly weaker prior to the 2009 major SSW than prior to the 2007 or 2008 major SSWs.

\section{Southern Hemisphere planetary wave activity}

The amplitudes of the $60^{\circ} \mathrm{S}-70^{\circ} \mathrm{S}$ eastward and westward travelling planetary waves at $30 \mathrm{~km}$ are shown in Fig. 11, while the stationary wave amplitudes are displayed in Fig. 12. While, as usual, no SSWs occurred in the Southern Hemisphere during these years, significant interannual variability in wave activity is noted. In particular, a large amount of eastward wave activity is present during spring 2006, lasting until December, as previously reported by Shepherd and Tsuda (2008). This amount of travelling wave activity was not observed so late in the following two seasons, although the E1 waves were stronger earlier during the 2007 and 2008 springs. Dominant periods of the E1 waves were around 10, 12 and 16 days, as well as one 30 day peak during August 2007. The wave periods were shorter for E2 with distinct peaks around 10-12 days, similar to that observed previously (Shiotani et al., 1990). As expected climatologically, the westward propagating waves are generally negligible, with the exception of some W1 with periods around 30 days in both spring 2006 and 2008. The 

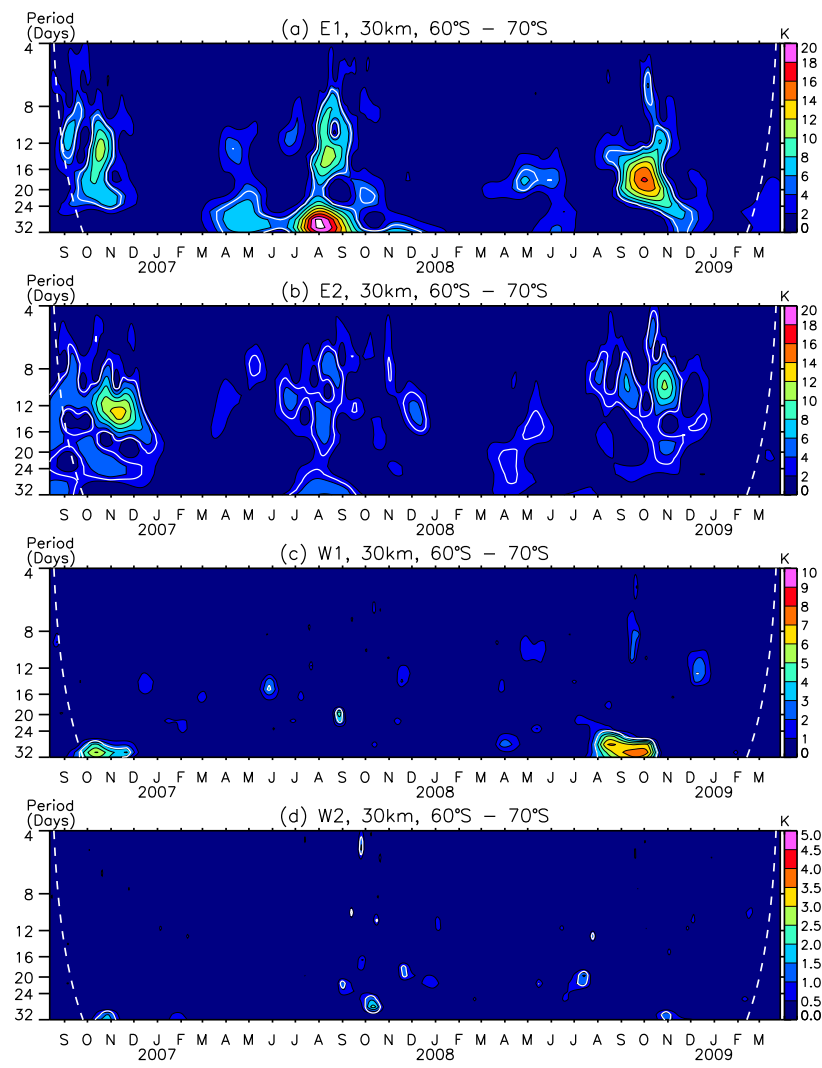

Fig. 11. The $60^{\circ} \mathrm{S}-70^{\circ} \mathrm{S}$ travelling planetary wave temperature wavelet amplitudes for: (a) E1, (b) E2, (c) W1, (d) W2.

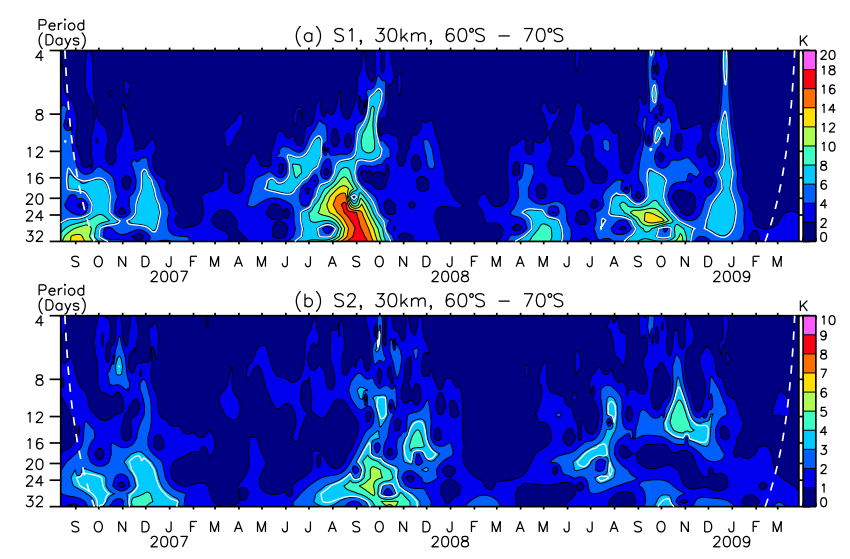

Fig. 12. The $60^{\circ} \mathrm{S}-70^{\circ} \mathrm{S}$ stationary planetary wave temperature wavelet amplitudes for: (a) S1 and (b) S2.

stationary waves also vary with time. In particular, relatively strong S1 and S2 with periods $>20$ days are observed during spring 2007, similar in time to the largest observed E1 activity.
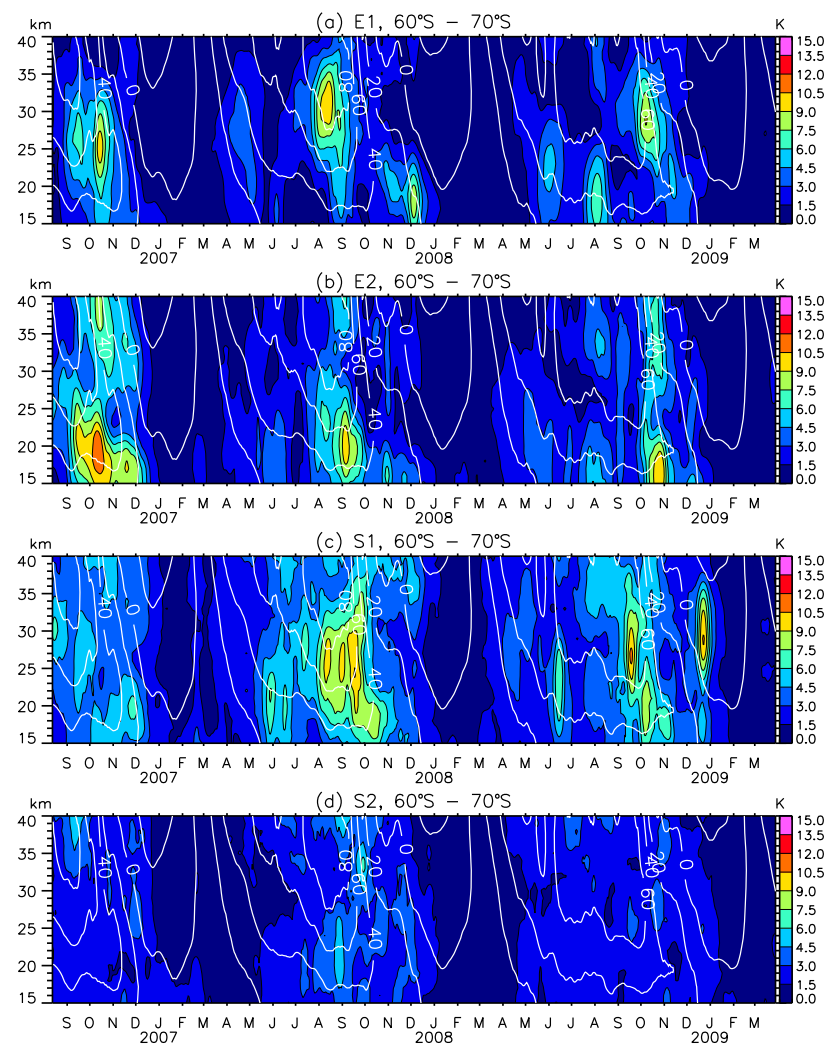

Fig. 13. The reconstructed 4-32 day mean stationary planetary wave amplitudes in height and time at $60^{\circ} \mathrm{S}-70^{\circ} \mathrm{S}$ for: (a) E1, (b) E2, (c) S1, (d) S2. Fifteen day smoothed UKMO zonal mean zonal winds (white, units of $\mathrm{m} \mathrm{s}^{-1}$, solid eastward) are also marked.

The eastward travelling and stationary amplitudes, reconstructed from the wavelet analysis for waves with periods of 4-32 days, are shown as a function of height and time in Fig. 13. Given the small and often insignificant nature of the westward travelling waves observed in Fig. 11, we do not discuss their amplitude variation with height and time. Waves exhibit an overall downward movement in their amplitudes through spring, following the zonal mean zonal winds. As with the Northern Hemisphere, the planetary wave amplitudes vary substantially in height and time on short scales. Note the persistence of many waves below $20 \mathrm{~km}$ into December each year, some of which still maintain relatively large amplitudes (e.g. E1 during 2007 and E2 during 2006). The E1 has a distinct amplitude peak at $30 \mathrm{~km}$, with a separate increase below $20 \mathrm{~km}$ in November and December during both 2007 and 2008. In contrast, the E2 is characterised in spring by large amplitudes at $15-20 \mathrm{~km}$, low amplitudes around $25-30 \mathrm{~km}$, and an increase in amplitude with altitude above that. The stationary waves vary markedly between years, with spring 2007 dominating the amplitudes below $25 \mathrm{~km}$. Amplitudes of $\mathrm{S} 1$ peaked around $25 \mathrm{~km}$ during August 2007, whereas during spring 2006, its amplitudes were 
weak and showed no preference for a specific height at which a maximum was to be found. The $2008 \mathrm{~S} 1$ were likewise very intermittent, with activity in September and mid December, both peaking around $27-30 \mathrm{~km}$. The vertical structure of S2 reveals increasing amplitudes above $30 \mathrm{~km}$ during all springs, although S2 during spring 2008 were relatively weak and variable in time and height. Only during 2007 is there consistently large S2 noted below $25 \mathrm{~km}$, where it peaked at $20 \mathrm{~km}$ in early September. The other two years had almost negligible $\mathrm{S} 2$ below $25 \mathrm{~km}$.

\section{Discussion}

The resolution of COSMIC enables a detailed analysis of the variability of planetary waves on vertical scales irresolvable with most present re-analysis data (Figs. 9, 10, 13). In both hemispheres, different planetary waves have maximum amplitudes at specfic heights. Superimposed upon the seasonal changes in planetary wave activity are fluctuations in wave amplitude on the order of a few weeks and a few kilometres in altitude. These short-lived changes are comparable in amplitude to those that occur over wider time and height scales ( $>$ a few weeks and on the order of 5-10 km). For example the short-lived E1 at $60^{\circ} \mathrm{S}-70^{\circ} \mathrm{S}$ during December 2007 had similar amplitude to the largest E1 during spring 2006 (Fig. 13a). Inter-annual variability of planetary wave amplitudes as a function of height is apparent in both hemispheres. These are often related to the minor and major SSWs in the Northern Hemisphere. Some of these waves were also of short duration and with COSMIC two distinct peaks centred on $22 \mathrm{~km}$ and $35 \mathrm{~km}$ in W2 during the 2009 Arctic SSW were recorded, with these enhancements observed on vertical scales less than $5 \mathrm{~km}$.

Large eastward wave activity in the Arctic with various periods preconditions the stratospheric circulation prior to the 2006-2007 and 2007-2008 SSWs, as expected climatologically (Labitzke, 1981; Limpasuvan et al., 2004) and observed during the recent Northern Hemisphere winters of 2003-2004 (Pancheva et al., 2008b) and 2005-2006 (Hoffmann et al., 2007). Eastward wave amplitudes dropped sharply immediately prior to the onset of the major SSW in late February 2008 (Fig. 9), consistent with the general development of an $s=1$ major warming (Labitzke, 1977; Krüger et al., 2005). In contrast, the eastward wave amplitudes for 2008-2009 were substantially smaller than the two preceding winters during the pre-warming period, although their maxima were still at similar altitudes $(30-35 \mathrm{~km}$ for E1 and $15-25 \mathrm{~km}$ for E2) and the wave periods were similar ( 16-20 days). Increasing amplitudes of the westward propagating waves occurred immediately prior to the large decrease in zonal mean zonal wind during 2008 and 2009, with maximum westward wave activity occurring after cessation of large eastward wave activity. Amplification of stationary planetary wave activity during the three Arctic winters demonstrate the role they play in causing some of the SSWs. This is especially apparent during 2009 for S2 (Fig. 10b), where large amplitude waves over a short temporal duration occurred throughout the entire height range considered (however, similar amplitudes of S2 during all three Decembers are noted). This is in contrast with the lower amplitudes of S2 during the preceding winters, even during the major SSWs of 2007 and 2008. The picture of strong $s=1$ prior to the 2009 major SSW and comparable $s=2$ during the event is consistent with the splitting of the polar vortex discussed by Manney et al. (2009).

Significantly more eastward wave activity is noted than westward wave activity in both hemispheres upon removal of the stationary wave components (Figs. 7 and 11). Planetary waves in the Southern Hemisphere are known to be either stationary or eastward propagating (e.g. Hartmann, 1976; Shiotani et al., 1990). However, a number of previous observations in the Northern Hemisphere have shown that westward travelling waves dominate the geopotential height and wind fields (e.g. Speth and Madden, 1983; Pancheva et al., 2008b). Westward travelling waves are essentially free external modes with no vertical phase tilts in adiabatic, frictionless conditions (Salby et al., 1984). These waves are likely to have weaker signals in the temperature field because of their nearly barotropic structure. An independent analysis of MLS temperature fields in recent winters reveals similar wave structure to that shown above (C. Meek, personal communication, 2009). Relative differences between the temperature and geopotential height structure of stratospheric planetary waves during the 2009 major SSW are discussed by Labitzke and Kunze (2009). Westward planetary wave activity observed by COSMIC was confined to the two major SSW events of 2008 and 2009, where periods of 12 days, 30 days (for $\mathrm{W} 1$ ) and $8-12$ days, 20 days and 30 days (for W2) were recorded. The presence of E2 waves with periods around 10 days at $60^{\circ} \mathrm{S}$ was observed at $10 \mathrm{hPa}$ (close to $30 \mathrm{~km}$ geometric altitude) in spring by Shiotani et al. (1990). E2 waves of similar periods were also observed in the COSMIC data in each of the three Antarctic springs (Fig. 11b), although the E2 waves were of larger amplitude at $15-20 \mathrm{~km}$ and above $35 \mathrm{~km}$ than at $30 \mathrm{~km}$ (Fig. 13).

\section{Conclusions}

Temperature data from the COSMIC GPS-RO satellite constellation were used to study the distribution and varibility of planetary wave activity in the low to mid- stratosphere (15$40 \mathrm{~km}$ ) of the Arctic and Antarctic from September 2006 until March 2009. Stationary waves were separated from travelling waves and their amplitudes, periods and small-scale vertical distribution then examined. One major SSW occurred during each of the three boreal winters considered here, including the record-breaking 2009 SSW. Several minor SSWs occurred during winters 2006-2007 and 2007-2008. 
The periods of the planetary waves observed during these winters are in general agreement with those previously reported. However, COSMIC also observed short lived but large increases in planetary wave amplitudes occurring regularly throughout all winters in both hemispheres. The extent of these fluctuations in amplitude was less than $5 \mathrm{~km}$ vertically and less than two weeks in time. These smallscale changes in planetary waves are significant, sometimes approaching the amplitude of the broader scale phenomena, which are observed on monthly or seasonal time scales and over greater vertical extents.

While the 2007 and 2008 Arctic major SSWs followed the normal development of an $s=1$ major warming, eastward wave activity prior to the 2009 major SSW was significantly reduced, although its periods were similar to previous years $(\sim 16-20$ days with some weaker waves with periods around 8 days and 12 days). Instead, very large S2 (period $>20$ days) and two distinct peaks in altitude of W2 (at $22 \mathrm{~km}$ and early in time at $35 \mathrm{~km}$ ) dominated the Arctic lower stratosphere in the weeks prior to the 2009 SSW. At this time, stationary waves with period $<20$ days were comparable between S1 and S2. Considering the whole winter overall, eastward waves were still more prevalent than westward waves. The S1 and E1 planetary wave amplitudes were much smaller during the early part of the 2008-2009 winter than during the two prior winters.

In the Southern Hemisphere, significant inter-annual variability in planetary wave amplitudes and periods were recorded, with the times of cessation of significant activity also varying. The height structure of planetary wave amplitudes also exhibited fluctuations on short time and vertical scales which are superimposed upon this broader seasonal cycle. Seasonal peak S1 and E1 amplitudes occurred around 25-30 km during the three springs, while the S2 and E2 have a seasonal peak around $20 \mathrm{~km}$, decreasing amplitudes up to $30-35 \mathrm{~km}$, and an increase above $35 \mathrm{~km}$.

Acknowledgements. COSMIC data were obtained from the COSMIC Data Analysis and Archive Center (CDAAC). We thank the COSMIC/FORMOSAT-3 Science Team for making the data available. We would like to thank T. Tsuda, Y. Kawatani, A. Klekociuk, and $\mathrm{C}$. Meek for valuable discussions and advice throughout the course of this research. We thank three anonymous reviewers whose helpful comments improved the original manuscript. This research was conducted for project 3140 of the Australian Antarctic programme.

Edited by: M. Dameris

\section{References}

Alexander, S. P., Tsuda, T., and Kawatani, Y.: COSMIC GPS Observations of Northern Hemisphere winter stratospheric gravity waves and comparisons with an atmospheric general circulation model, Geophys. Res. Lett., 35, L10808, doi:10.1029/ 2008GL033174, 2008a.

Alexander, S. P., Tsuda, T., Kawatani, Y., and Takahashi, M.: Global distribution of atmospheric waves in the equatorial upper troposphere and lower stratosphere: COSMIC observations of wave mean flow interactions, J. Geophys. Res., 113, D24115, doi:10.1029/2008JD010039, 2008b.

Alexander, S. P., Klekociuk, A. R., and Tsuda, T.: Gravity wave and orographic wave activity observed around the Antarctic and Arctic stratospheric vortices by the COSMIC GPS-RO satellite constellation, J. Geophys. Res., 114, D17103, doi:10.1029/ 2009JD011851, 2009.

Andrews, D. G., Holton, J. R., and Leovy, C. B.: Middle Atmosphere Dynamics, Academic Press, 1987.

Anthes, R. A., Bernhardt, P. A., Chen, Y., Cucurull, L., Dymond, K. F., Ector, D., Healy, S. B., Ho, S. P., Hunt, D. C., Kuo, Y. H., Liu, H., Manning, K., McCormick, C., Meehan, T. K., Randel, W. J., Rocken, C., Schreiner, W. S., Sokolovskiy, S. V., Syndergaard, S., Thompson, D. C., Trenberth, K. E., Wee, T. K., Yen, N. L., and Zeng, Z.: The COSMIC/FORMOSAT-3 Mission Early Results, Bull. Amer. Meteor. Soc., 89, 313-333, doi: 10.1175/BAMS-89-3-313, 2008.

Baldwin, M. P. and Dunkerton, T. J.: Propagation of the Arctic Oscillation from the stratosphere to the troposphere, J. Geophys. Res., 104, 30937-30946, 1999.

Chshyolkova, T., Manson, A. H., Meek, C. E., Avery, S. K., Thorsen, D., MacDougall, J. W., Hocking, W., Murayama, Y., and Igarashi, K.: Planetary wave coupling in the middle atmosphere (20-90 km): A CUJO study involving TOMS, MetO and MF radar data, Ann. Geophys., 23, 1103-1121, 2005.

Chshyolkova, T., Manson, A. H., Meek, C. E., Avery, S. K., Thorsen, D., MacDougall, J. W., Hocking, W., Murayama, Y., and Igarashi, K.: Planetary wave coupling processes in the middle atmosphere (30-90 km): A study involving MetO and MFR data, J. Atmos. Sol. Terr. Phys., 68, 358-368, 2006.

Ern, M., Preusse, P., Krebsbach, M., Mlynczak, M. G., and Russell III, J. M.: Equatorial wave analysis from SABER and ECMWF temperatures, Atmos. Chem. Phys., 8, 845-869, 2008, http://www.atmos-chem-phys.net/8/845/2008/.

Ern, M., Lehmann, C., Kaufmann, M., and Riese, M.: Spectral wave analysis at the mesopause from SCIAMACHY airglow data compared to SABER temperature spectra, Ann. Geophys., 27, 407-416, 2009.

Fraedrich, K. and Böttger, H.: A wavenumber-frequency analysis of the $500 \mathrm{mb}$ geopotential at $50^{\circ} \mathrm{N}, \mathrm{J}$. Atmos. Sci., 35, 745-750, 1978.

Hartmann, D. L.: The structure of the stratosphere in the Southern Hemisphere during late winter 1973 as observed by satellited, J. Atmos. Sci., 33, 1141-1154, 1976.

Hartmann, D. L., Mechoso, C. R., and Yamazaki, K.: Observations of wave mean flow interaction in the Southern Hemisphere, J. Atmos. Sci., 41, 351-162, 1984.

Hayashi, H., Furumoto, J., Lin, X., Tsuda, T., Shoji, Y., Aoyama, Y., and Maruyama, Y.: Validation of refractivity profiles retrieved from FORMOSAT-3/COSMIC radio occultation sound- 
ings: Preliminary results of statistical comparisons utilizing balloon-borne observations, Terr. Atmos. Ocean. Sci., 20, 51-58, doi:10.3319/TAO.2008.01.21.01(F3C), 2009.

Hayashi, Y.: A generalized method of resolving disturbances into progressive and retrogressive waves by space Fourier and time cross-spectral analysis, J. Met. Soc. Japan, 49, 125-128, 1971.

Hayashi, Y. and Golder, D. G.: Space-time spectral analysis of midlatitude disturbances appearing in a GFDL general circulation model, J. Atmos. Sci., 34, 237-262, 1977.

Hirooka, T.: Normal mode Rossby waves as revealed by UARS/ISAMS observations, J. Atmos. Sci., 57, 1277-1285, 2000.

Hirooka, T. and Hirota, I.: Normal mode Rossby waves observed in the upper stratosphere. Part II: Second antisymmetric and symmetric modes of zonal wavenumbers 1 and 2, J. Atmos. Sci., 42, 536-548, 1985.

Hirota, I. and Hirooka, T.: Normal mode Rossby waves observed in the upper stratosphere. Part I: First symmetric modes of zonal wavenumbers 1 and 2, J. Atmos. Sci., 41, 1253-1267, 1984.

Hoffmann, P., Singer, W., Keuer, D., Hocking, W. K., Kunze, M., and Murayama, Y.: Latitudinal and longitudinal variability of mesospheric winds and temperatures during stratospheric warming events, J. Atmos. Sol. Terr. Phys., 69, 2355-2366, 2007.

Kawatani, Y., Takahashi, M., Sato, K., Alexander, S. P., and Tsuda, T.: Global distribution of atmospheric waves in the equatorial upper troposphere and lower stratosphere: AGCM simulation of sources and propagation, J. Geophys. Res., 114, D01102, doi: 10.1029/2008JD010374, 2009.

Krüger, K., Naujokat, B., and Labitzke, K.: The unusual midwinter warming in the Southern Hemisphere stratosphere 2002: A comparison to Northern Hemisphere phenomena, J. Atmos. Sci., 62, 603-613, 2005.

Kursinski, E. R., Hajj, G. A., Schofield, J. T., Linfield, R. P., and Hardy, K. R.: Observing Earth's atmosphere with radio occultation measurements using the Global Positioning System, J. Geophys. Res., 102, 23429-23465, 1997.

Labitzke, K.: Interannual variability of the winter stratosphere in the Northern Hemisphere, Mon. Weather Rev., 105, 762-770, 1977.

Labitzke, K.: The amplification of height wave 1 in January 1979: A characteristic precondition for the major warming in February, Mon. Weather Rev., 109, 983-989, 1981.

Labitzke, K. and Kunze, M.: On the remarkable Arctic winter in 2008/2009, J. Geophys. Res., 114, D00102, doi:10.1029/ 2009JD012273, 2009.

Labitzke, K. and Naujokat, B.: The lower Arctic stratosphere in winter since 1952, SPARC Newsl., 11-14, 2000.

Leovy, C. B. and Webster, P. J.: Stratospheric long waves: Comparison of thermal structure in the Northern and Southern Hemispheres, J. Atmos. Sci., 33, 1624-1638, 1976.

Limpasuvan, V., Thompson, D. W. J., and Hartmann, D. L.: The life cycle of the Northern Hemisphere sudden stratospheric warmings, J. Climate, 17, 2584-2596, 2004.

Liu, H. L. and Roble, R. G.: A study of a self-generated stratospheric sudden warming and its mesospheric-lower thermospheric impacts using the coupled TIME-GCM/CCM3, J. Geophys. Res., 107, 4695, doi:10.1029/2002JD001533, 2002.

Manney, G. L., Krüger, K., Sabutis, J. L., Sena, S. A., and Pawson, S.: The remarkable 2003-2004 winter and other recent warm winters in the Arctic stratosphere since the late 1990s, J. Geophys. Res., 110, D04107, doi:10.1029/2004JD005367, 2005.

Manney, G. L., Schwartz, M. J., Krüger, K., Santee, M. L., Pawson, S., Lee, J. N., Daffer, W. H., Fuller, R. A., and Livesey, N. J.: Aura Microwave Limb Sounder observations of dynamics and transport during the record-breaking 2009 Arctic stratospheric major warming, Geophys. Res. Lett., 36, L12815, doi:10.1029/ 2009GL038586, 2009.

Mechoso, C. R. and Hartmann, D. L.: An observational study of traveling planetary waves in the Southern Hemisphere, J. Atmos. Sci., 39, 1921-1935, 1982.

Pancheva, D., Mukhtarov, P., Mitchell, N. J., Andonov, B., Merzlyakov, E., Singer, W., Murayama, Y., Kawamura, S., Xiong, J., Wan, W., Hocking, W., Fritts, D., Riggin, D., C., M., and Manson, A.: Latitudinal wave coupling of the stratosphere and mesosphere during the major stratospheric warming in 2003/2004, Ann. Geophys., 26, 467-483, 2008 a.

Pancheva, D., Mukhtarov, P., Mitchell, N. J., Merzlyakov, E., Smith, A. K., Andonov, B., Singer, W., Hocking, W., Meek, C., Manson, A., and Murayama, Y.: Planetary waves in coupling the stratosphere and mesosphere during the major stratospheric warming in 2003/2004, J. Geophys. Res., 113, D12105, doi:10.1029/2007JD009011, 2008b.

Pawson, S. and Kubitz, T.: Climatology of planetary waves in the northern stratosphere, J. Geophys. Res., 101, 16987-16996, 1996.

Pogoreltsev, A. I., Kanukhina, A. Y., Suvorova, E. V., and Savenkova, E. N.: Variability of planetary waves as a signature of possible climatic changes, J. Atmos. Sol. Terr. Phys., 71, 15291539, 2009.

Randel, W. J.: A study of planetary waves in the southern winter troposphere and stratosphere. Part I: Wave stucture and vertical propagation, J. Atmos. Sci., 44, 917-935, 1987.

Salby, M. L., Hartmann, D. L., Bailey, P. L., and Gille, J. C.: Evidence for Equatorial Kelvin Modes in Nimbus-7 LIMS, J. Atmos. Sci., 41, 220-235, 1984.

Schreiner, W., Rocken, C., Sokolovskiy, S., Syndergaard, S., and Hunt, D.: Estimates of the precision of GPS radio occultations from the COSMIC/FORMOSAT-3 mission, Geophys. Res. Lett., 34, L04808, doi:10.1029/2006GL027557, 2007.

Shepherd, M. G. and Tsuda, T.: Large-scale planetary disturbances in stratospheric temperature at high-latitudes in the southern summer hemisphere, Atmos. Chem. Phys., 8, 7557-7570, 2008, http://www.atmos-chem-phys.net/8/7557/2008/.

Shiotani, M., Kuroi, K., and Hirota, I.: Eastward travelling waves in the southern hemisphere stratosphere during the spring of 1983 , Q. J. Roy. Meteorol. Soc., 116, 913-927, 1990.

Speth, P. and Madden, R. A.: Space-time spectral analyses of Northern Hemisphere geopotential heights, J. Atmos. Sci., 40, 1086$1100,1983$.

Torrence, C. and Compo, G. P.: A practical guide to wavelet analysis, B. Am. Meteor. Soc., 79, 61-78, 1998.

Tsuda, T., Nishida, M., Rocken, C., and Ware, R. H.: A global morphology of gravity wave activity in the stratosphere revealed by the GPS occultation data (GPS/MET), J. Geophys. Res., 105, 7257-7273, 2000.

Wang, L. and Alexander, M. J.: Gravity wave activity during stratospheric sudden warmings in the 2007/08 Northern Hemisphere winter, J. Geophys. Res., 114, D18108, doi:10.1029/ 
2009JD011867, 2009.

Watanabe, S., Kawatani, Y., Tomikawa, Y., Miyazaki, K., Takahashi, M., and Sato, K.: General aspects of a T213L256 middle atmosphere general circulation model, J. Geophys. Res., 113, D12110, doi:10.1029/2008JD010026, 2008.
Zhou, S., Miller, A. J., Wang, J., and Angell, J. K.: Downward propagating temperature anomalies in the preconditioned polar stratosphere, J. Climate, 15, 781-792, 2002. 